in the meteoritic hypothesis, each meteorite forming a molecule of a quasi-gas, the rotational theory would become more tenable.

Visibility of Faint Stars at the Lowell Observatory. - In No. 7, vol. xiii., of Popular Astronomy, Mr. Lowell publishes a chart and some figures which testify eloquently to the "seeing" and the instrumental efficiency at the Lowell Obseryatory, Flagstaff, Arizona.

In going over a chart of faint stars published by Prof. Tucker for magnitude comparisons, Mr. Lampland found that the faintest stars on the I.ick chart were perfectly visible at Flagstaff, although the aperture employed there is only 24 inches, whereas at Lick an aperture of 36 inches is available. In the region following $\delta$ Ophiuchi, one of Prof. Tucker's richest fields, I6I stars were shown on the Lick chart. Plotting the same field, independently, Mr. Lampland obtained 173 stars, the greatest increase occurring among the fainter objects. As I5 stars marked on the Lick charts were not found, it follows that 27 were actually seen at Flagstaff which were not recorded by Prof. Tucker. Mr. Lowell remarks that this result is not definitive of what may be charted at his observatory, as moonlight and the rainy season both acted as drawbacks in the present test.

Tile Orbit of $\zeta$ Tauri.-The spectroscopic binary $\zeta$ lauri was included in a list of such objects published by Profs. Frost and Adams in vol. xvii. of the Astrophysical Journal, and attention was then directed to the peculiar spectrum of this star. Because of this peculiarity, and also on account of its long period, this object has since been observed regularly at the Yerkes Observatory, and Prof. Adams has determined the orbit, the determination being based on the measurements of the line $\mathrm{H \gamma}$ on twenty-five plates. Owing to the grcat breadth of this line duplicate measures were made throughout, and, with the exception of one plate, which was rejected in the discussion, they agreed reasonably well.

The following elements were obtained as a result of the research :-

$$
\begin{aligned}
& u_{1}=100^{\circ} \mathrm{I} 3^{\prime} \\
& \omega=9^{\circ} 45^{\prime} \\
& e=0.180^{\prime} \\
& T=1902 \text { Jan. } 19.9
\end{aligned}
$$

$a \sin i=27.900,000 \mathrm{~km}$. Period $\mathrm{U}=138$ days $\mu=2^{\circ} \cdot 609$

The largest residual is $-3.1 \mathrm{~km}$., which, considering that the determination is based upon the measurements of only one line, is regarded as satisfactory. No trace of the spectrum of the second component has been found on any of the plates yet secured (Astrophysical Journal, September).

The Constant of Aberration.-As the result of a laborious discussion of more than 15,000 observations, Prof. Doolittle has arrived at the value $2 \mathrm{O}^{\prime \prime} .54$ for the constant of aberration. In publishing this result Prof. Doolittle states that no reasonable weighting of the values will alter it more than $\mathrm{O}^{\prime \prime} . \mathrm{or}$. The above value agrees very well with the statement made in 1903 by Prof. Chandler, after a very complete investigation, that the real value would be found to be $20^{\prime \prime} \cdot 5^{2}$, or slightly higher (the Observatory, No. 361).

The Natal Government Observatory.-Mr. Nevill's report of the work done in the Natal Government Observatory during I904 contains but few references to purely astronomical observations, the chief function of the observatory being distinctly meteorological.

\section{THE OPENING OF THE MEDICAL SESSION IN LONDON.}

$A^{S}$ is customary, the opening of the medical session has been made the occasion at several of the schools for the distribution of prizes and the delivery of interesting addresses.

At University College, Prof. Kenwood gave an address on "Preventive Medicine, Past and Present," in the course of which he directed attention to the important position occupied by medical practitioners as guardians of the public health, and emphasised the necessity for the adequate teaching of hygiene and public health in the medical NO. I 876 , VOL. 727 schools. He then dealt with the condition of things which should cbtain in a hygienic Utopia, and pointed out that while typhus fever had been practically banished and the mortality from scarlatina reduced 80 per cent. during the past thirty years, that from measles had increased. As regards the statement that the practice of hygiene and preventive medicine tends to the preservation of the physically unfit, there is doubtless both a credit and a debit side to the account, and there can be little doubt that the credit side presents a splendid balance.

At King's College the session was opened by Prof. Clifford Allbutt, F.R.S., with an address on "Medical Education." Prof. Allbutt said that in medical education London had its own problems and difficulties, but these could only be solved on principles common to education everywhere and always.

Education must always consist of two parts-the earlier a drawing forth and refining of all the faculties and such a formation of them as habits that a right reason and virtue became easy and pleasant to us; the later the adaptation of these faculties to particular callings. The methods of specific or technical educations were pretty clearly seen; their difficulty was only the difficulty of persuading the British parent of the value of any education whatever, and of the importance of providing for it money, equipment, and time.

The university should be responsible only for a certain universal character of the mind and imagination, a training which could be given in any one of many " faculties." The five years' professional course, all too brief as it was, was now much too heavily loaded. The preliminary sciences occupied so far the larger half of it that little more than a year and a half had to suffice for the study of medicine in all its divisions and subdivisions; and yet upon that formidable burden of subjects some enthusiasts were yearning to pile more and more. The reform which was needed was to teach fewer subjects and to teach them broadly and accurately. In the five years' technical course we ought to begin with the two subiects anatomy and physiology, and teach them on university methods. No subjects made a finer training for hand and mind.

At St. George's Hospital the introductory address was delivered by Mr. Brudenell Carter, who also dealt with medical education and the importance of research. $\mathrm{He}$ expressed the opinion that a real and thorough training in physics should form, and eventually must form, the cssential groundwork of medical education. Next in importance to physics, as a preliminary subject, he would place such a study of language, it may be of one language alone, as would enable the learner to form clear ideas himself and to express those ideas in a manner clearly intelligible to others.

At Charing Cross Hospital, Sir James Crichton-Browne delivered one of his characteristic addresses. He declared that we have hordes of undergrown, underfed, blemished, diseased, debilitated men, women, and children, who are industrially and socially inefficient; that many of our public institutions are as incompetent as the valves of a damaged heart, and that our educational machinery, our economic system, our municipal administration, and our Army are all inefficient.

If they were to be efficient medical men they must improve their personal efficiency, and see to it that they were physically efficient, intellectually efficient, and morally efficient. For facilitating the attainment of these desirable ends Sir James formulated a series of precepts or principles by which they should be guided.

$\mathrm{He}$ dwelt on the necessity for proper exercise and recreation, for proper meals, and for a sufficiency of sleep, declaring that the medical student should have regularly nine hours' sleep in the twenty-four.

At the Middlesex Hospital, Dr. R. A. Young took for his theme "Method in Medicine," and dealt with the need for method in teaching and in study, in research and in practice.

At St. Mary's Hospital an address on "The Public and Medical Education "was given by Dr. Wilfred Harris, in which he stated his conviction that concentration of teaching in the preliminary and intermediate subjects at one or a few centres would make for efficiency, and that one State-controlled examination should take the place of the present multitude of degree and diploma-giving bodies. 
Mrs. Bryant, in the course of an address on "Ideals of Study " at the London School of Medicine for Women, said that an ideal of study was most usefully conceived, not as a scheme of learning to be achieved, but rather in its psychological essence as growing out of the primitive intellectual interests of human beings. Interest in knowledge for its own sake-the theoretic interest-was to be found more or less in every healthy normal person. According to brain type, habit, association, and other circumstances, its bent towards one or another branch of knowledge varied in individuals.

It was suggested that more should be done in elementary and secondary education ( $\mathrm{I}$ ) to develop the practical interest in relation to all the every-day problems arising naturally in the environment; and (2) to train it to a high ideal of the science and skill involved in their solution. The neglect of the practical interest in the practically minded was not only loss of good material for practical efficiency; it was also the loss of opportunity for the cultivation of the scientific interest. To inquire how a thing was made led to inquiry as to its causation, and at that point the youth or child becomes athirst for science.

At the London School of Tropical Medicine, Dr. George Nuttall, F.R.S., delivered an address on "Scientific Research in Medicine," in the course of which he pointed out the great benefits to mankind which have followed such discoveries as those of the causes and prevention of yellow fever and malaria, and that the majority of such discoveries have been made by those engaged in research and in the realms of pure science, and rarely by those guided by principles of direct and immediate utility. $\mathrm{He}$ urged the necessity for the endowment of research, particularly in experimental medicine, and finally proceeded to review recent work in protozoology and parasitology.

At the School of Pharmacv, Pharmaceutical Society of Great Britain, Sir Boverton Redwood delivered the address on "General Study and Specialism," and at the Royal Veterinary College Mr. Hunting discussed the career of members of the veterinary profession.

\section{DIAMONDS. ${ }^{1}$}

F ROM the earliest times the diamond has fascinated mankind. It has been a perennial puzzle one of the " riddles of the painful earth." It is recorded in "Sprat's History of the Royal Society" (I667) that among the questions sent by order of the society to Sir Philiberto Vernatti, resident in Batavia, was one inquiring "Whether Diamonds grow again after three or four years in the same places where they have been digged out?' The answer sent back was "Never, Or at least as the memory of man can attain to.'

Of late years the subject has fascinated many men of science. The development of electricity, with the introduction of the electric furnace, has facilitated research, and I am justified in saying that if the diamond problem is not actually solved, there is every probability it shortly will be solved.

South Africa, as I will show in detail, is the favourite haunt of diamonds on this planet : it ranks with Australia and California as one of the three great gold-vielding regions. But the wealth of South Africa is not limited to gold and diamonds. It is also the illimitable home of coal-" the black diamond" of the universe. The province of Natal alone contains more coal than Britain ever owned before a single bucket had been raised; and the coal beds extend into the Orange River Colony. Valuable iron ores exist also in large quantities.

The Pipes at Kimberley.

The five diamond mines are all contained in a precious circle $3^{\frac{1}{2}}$ miles in diameter. They are irregular shaped round or oval pipes, extending vertically downwards to unknown depths, retaining about the same diameter throughout. They are considered to be volcanic necks, filled from below with a heterogeneous mixture of fragments of surrounding rocks, and of older rocks such as granite, mingled and cemented with a bluish coloured hard

1 Abridged from a lecture Neliverar before the British Associzion at Kimberiey on September 5 by Sir William Crookes, F.R.S.

NO. I 876 , vOL. 72$]$ clayey mass, in which famous blue clay the imbedded diamonds are hidden.

How the great pipes were originally formed is hard to say. They were certainly not burst through in the ordinary manner of volcanic eruption, since the surrounding and enclosing walls show no signs of igneous action, and are not shattered or broken up even when touching the "blue ground." It is pretty certain these pipes were filled from below after they were pierced, and the diamonds were formed at some previous time and mixed with a mud volcano, together with all kinds of débris eroded from the rocks through which it erupted, forming a geological "plum pudding." The direction of flow is seen in the upturned edges of some of the strata of shale in the walls, although I was unable to see any upturning in most parts of the walls of the De Beers mine at great depths.

The breccia filling the mines, usually called "blue ground," is a collection of fragments of shale, and of various eruptive rocks, boulders, and crystals of many kinds of minerals. Indeed, a more wildly heterogeneous mixture can hardly be found anywhere else on this globe. The Kimberley mines for the first 70 feet or 80 feet are filled with so-called "yellow ground," and below that with "blue ground." This superposed yellow on blue is common to all the mines. The blue is the aboriginal ground, and owes its colour chiefly to the presence of lower oxides of iron. When atmospheric influences have access to the iron it becomes peroxidised, and the ground assumes a yellow colour. The thickness of yellow earth in the mines is therefore a measure of the depth of penetration of air and moisture. The colour does not affect the yield of diamonds. The ground mass is soapy to the touch and friable, especially after exposure to weather. Besides diamonds, more than eighty species of minerals have been recognised in the blue ground, the most common being magnetite, ilmenite, garnet, bright green ferriferous enstatite (bronzite), a hornblendic mineral closely resembling smaragdite, calc-spar, vermiculite, diallage, jeffreysite, mica, kyanite, augite, peridot, iron pyrites, wollastonite, vaalite, zircon, chrome iron, rutile, corundum, apatite, olivine, sahlite, chrómite, pseudobrookite, perofskite, biotite, and quartz.

The blue ground does not show any signs of igneous action; the fragments in the breccia are not fused at the edges. The eruptive force was probably steam or watergas, acting under great pressure but at no high temperature.

There are many such pipes in the immediate neighbourhood of Kimberley. It may be that each volcanic pipe is the vent for its own special laboratory-a laboratory buried at vastly greater depths than we have yet reached -where the temperature is comparable with that of the electric furnace, where the pressure is fiercer than in our puny laboratories and the melting point higher, where no oxygen is present, and where masses of liquid carbon have taken centuries, perhaps thousands of years, to cool to the solidifying point. The chemist arduously manufactures infinitesimal diamonds, valueless as ornamental gems; but nature, with unlimited temperature, inconceivable pressure, and gigantic material, to say nothing of measureless time and appalling energy, produces without stint the dazzling, radiant, beautiful, coveted crystals I am enabled to show you to-night.

This hypothesis of the origin of diamonds is in many ways corroborated.

The ash left after burning a diamond invariably contains iron as its chief constituent; and the most common colours of diamonds, when not perfectly pellucid, show various shades of brown and yellow, from the palest "off colour " to almost black. They are also green, blue, pink, yellow, and orange. These variations give support to the theory advanced by Moissan that the diamond has separated from molten iron-a theory of which I shall say more presently-and also explain how it happens that stones from different mines, and even from different parts of the same mine, differ from each other. Further confirmation is given by the fact that the country round Kimberley is remarkable for its ferruginous character, and ironsaturated soil is popularly regarded as one of the indications of the near presence of diamonds. Along with carbon, molten iron dissolves other bodies which possess 